\title{
Energy- and Indoor-Related Information for Office Occupants: What do They Really Want
}

\author{
Sami Karjalainen*, Janne Peltonen \\ VTT Technical Research Centre of Finland Ltd, Espoo, Finland \\ Email address: \\ Sami.Karjalainen@vtt.fi (S. Karjalainen), Janne.Peltonen@vtt.fi (J. Peltonen) \\ *Corresponding author
}

\section{To cite this article:}

Sami Karjalainen, Janne Peltonen. Energy- and Indoor-Related Information for Office Occupants: What do They Really Want. International Journal of Energy and Power Engineering. Vol. 5, No. 3, 2016, pp. 113-120. doi: 10.11648/j.ijepe.20160503.14

Received: April 21, 2016; Accepted: June 2, 2016; Published: June 7, 2016

\begin{abstract}
A number of studies have shown that feedback on users' own energy consumption can be effective in reducing household energy consumption. Almost all the studies on presenting energy feedback relate to in-home displays and domestic environments, only a few concern other contexts. Building automation systems in modern office buildings collect a large amount of energy- and indoor-related measurements. In this study, the primary interest lies in how energy- and indoor-related measurements could be used to increase energy awareness and occupant satisfaction. The purpose of this work is to study the preferences of office occupants and to find out what kind of information they are interested in. A questionnaire was delivered to two buildings in Finland. The total number of respondents was 151. The results show that the respondents were more interested in receiving indoor-related information than energy-related information. They were especially interested in knowing the room temperature in their own office. Almost half of them were not interested in energy-related information since they chose none of the energy-related options. The most effective ways to increase energy conservation in offices are discussed.
\end{abstract}

Keywords: Energy Feedback, Energy Awareness, Building Automation, Occupant Behaviour, Behaviour Change, Occupant Satisfaction, Room Temperature, Indoor Air Quality

\section{Introduction}

Concerns about environmental impacts had made energy conservation in buildings become a topic of increasing interest. The Fifth Assessment Report of the Intergovernmental Panel on Climate Change (IPCC) show that buildings represent a critical piece of a low-carbon future [1]. The IPCC report notes that behaviour, lifestyle and culture have a major effect on buildings' energy use which account for $32 \%$ of total global energy use.

\subsection{Energy Feedback for Households}

The importance of feedback on consumers' own energy consumption is widely accepted. A number of studies have shown that feedback can be effective in reducing household energy consumption, see reviews by Darby [2], Abrahamse et al. [3], Fischer [4], Ehrhardt-Martinez et al. [5] and Faruqui et al. [6].

It is clear that the savings are dependent on the type and quality of the feedback. This means that care must be taken when choosing the information consumers are given and the way in which it is presented. It is important that the information provided to consumers is easy to understand and relevant, and that it enables them to make sustainable decisions about their energy use.

Little is known about how the design details of energy monitors impact energy use. Recent studies (reviewed here) have given some insight into how the energy monitors should be designed to increase energy awareness.

Karjalainen [7] introduced user interface prototypes to consumers in qualitative interviews and found that the following features of electricity consumption feedback are most valued by consumers: presentations of costs, appliance-specific breakdowns (information on how much each appliance consumes proportionally) and historical comparisons (comparison with the consumer's own prior consumption). According to the study, people can interpret various kinds of charts and tabular presentations if they are well designed, but many have problems understanding 
scientific units, including the difference between $\mathrm{W}$ and kWh.

Krishnamurti et al. [8] found that consumers prefer appliance-specific breakdowns and presentations of costs but learn better from other types of information. Their laboratory experiments show that the less-preferred aggregated $\mathrm{kWh}$ feedback was effective for learning the relative electricity consumption of single appliances. However, they suggest providing projected monthly costs by appliance if the desired knowledge goal is to understand the relative costs.

Jain et al. [9] compared the following design components for energy monitors in a six week empirical study: normative comparison, historical comparison, incentives, rewards and penalization, and disaggregation. The results show that historical comparison and incentives led to the highest engagement and energy savings.

Jain et al. [10] examined empirically the impact that information presentation has on energy consumption behaviour in a residential building. A comparison between feedback in energy units $(\mathrm{kWh})$ and feedback in environmental externality units (equivalent number of trees) was performed. The results show that participants who received feedback in $\mathrm{kWh}$ increased consumption by $18 \%$ and those who received feedback in equivalent number of trees reduced consumption by $10 \%$ on average.

Hargreaves et al. [11] present results of a field trial of real-time energy monitors. They conclude that the monitors need to look good to fit in the households and the information provided needs to be clear, transparent and flexible. Information should be presented in variable formats and, perhaps, be customisable.

Chiang et al. [12] performed laboratory experiments to compare numerical design (just numbers), analogue design (fuel gauge type presentation) and ambient design (simplified face symbols) in the context of energy displays. The results show that numerical displays were superior in capturing attenuation to information and were also preferred by the participants.

In summary, feedback on own consumption can be effective in reducing energy consumption in households. We still have limited understanding on how feedback should be designed to be effective as possible. An important contribution to the knowledge was provided by Schwartz et al. [13]. They published a list of relevant features for the design of sustainable interaction. The version below is largely simplified:

- Feedback should inform us of energy waste, not just show kWh, $\mathrm{CO}_{2}$ or cost.

- Feedback should support the creation of an emotional bond with energy.

- Feedback should provide support for the practice of comparing the consumptions of appliances.

- Feedback should use money as a unit because money is an essential element in existing accounting practices.

- Feedback should provide appropriate means for comparable feedback and explore new strategies to include the social context of consumption.
- Feedback should have a connection to individual actions, for example, providing features to support the discovery of patterns and exceptions based on uses and habits.

\subsection{Energy Feedback for Office Occupants}

Almost all the studies on presenting energy feedback concern in-home displays and domestic environments. Only a few papers concern other contexts than the domestic one as noted by Pierce and Paulos [14] and Murtagh et al. [15]. The results for domestic environments cannot be transferred directly to other environments such as offices since the context affects the energy behaviours, see below.

The importance of studying other contexts than the domestic one is highlighted by the fact that energy consumption of the services sector is still growing. Between 2005 and 2012 the final energy consumption in the European Union decreased by $7 \%$ but the services sector increased consumption by $4 \%$ over the period [16]. This is due to the continued increase in the demand for electrical appliances like computers and other energy-intensive technologies such as air conditioning [16]. The electricity consumption in the services increased by $91 \%$ between 1990 and 2012 and $15 \%$ since 2005 [16]. In 2010 commercial buildings accounted for $8 \%$ of total global energy use [1].

Coleman et al. [17] found barriers to utilisation of energy-feedback technologies in offices since occupants are focused on work, accomplishing the tasks for which they were hired, instead of energy-saving activities. Occupants often feel that the only energy consumption under their direct control is that of their workstation equipment (e.g., computer, monitor, and desk lamp).

An interview-based study performed in Finland with 1,000 respondents showed that people make significantly less effort to save energy in offices than in homes [18]. Office occupants are less interested in energy consumption because they are not responsible for the energy costs and may consider their own consumption negligible [18]. A true context effect has also been found in the experience of thermal environments: similar thermal environments are felt differently in homes and offices [19-20].

Littleford et al. [21] performed a questionnaire study to examine how lighting and computer use behaviours in offices relate to similar behaviours by the same individuals in households. They found that the context had a major effect on behaviour. This suggests that the work or home setting is an important defining feature of the energy use behaviour.

Carrico and Riemer [22] performed two interventions to study the effect on energy consumption in an office environment. They gave group-level feedback via e-mail and used educators to disseminate information and encourage colleagues to reduce energy use. The feedback and peer education resulted in a $7 \%$ and $4 \%$ reduction in energy use, respectively.

Orland et al. [23] educated users and targeted behaviour change in offices through serious game-style interventions. They created an 'energy chicken' game in which chickens 
gain or decline in health in line with the energy consumption of a specific device. The average plug-load energy consumption was reduced by $13 \%$ : $7 \%$ on work days and $23 \%$ on non-work days.

Murtagh et al. [15] performed a field trial in an office environment to study the effect of individual feedback on energy use. A statistically significant reduction in energy consumption was found for months 3 and 4 but not for months 1 and 2, i.e. for some reason the feedback seemed to have an effect that developed slowly. Occupants consumed much more energy at their desks than they really needed but were not very prepared to change their behaviour. $41 \%$ of the office occupants did not access their worker-specific energy feedback even once. It was also found in the study that self-reported pro-environmental behaviour did not relate to actual energy behaviour, i.e. what participants said was different from what they did.

Handgraaf et al. [24] gave office occupants feedback on their energy consumption and compared the effect of monetary and social rewards on energy conservation. The public social rewards were found to be more effective than monetary rewards in reducing energy use.

Energy dashboards for promoting environmentally sustainable behaviour have been developed for students and office occupants [25]. Energy dashboards typically show real-time data and are often installed in hallways. Web-based applications may be used with personal devices. Very little information is available on the effectiveness of energy dashboards in reducing energy consumption. Börner et al. [26] created energy display applications for people working in office buildings. The mobile and desktop applications present real-time power $(\mathrm{W})$ and consumption $(\mathrm{kWh})$. Although the prototype received positive comments by the participants, the actual daily usage was not as frequent as expected. No results on the actual effect on energy consumption are presented in the paper.

In publications, energy dashboards are typically presented with no rationale for the design choices they embody. Very little is known about the impact of energy dashboards on energy use and how the design details affect that.

In summary, the context greatly affects the energy use behaviour and it seems to be challenging to modify energy behaviours in offices, let alone achieve a significant and permanent decrease in energy use.

\subsection{The Background of the Study}

The origin of this paper was a study which targeted in creating a small number of key performance indicators (KPIs) that focus on the critical aspects of building performance. Three groups of users - office occupants, maintenance personnel and building owners - were considered. The materials that were used to create the KPIs included a literature survey on building performance indicators and lists of building automation data from reference buildings. Two workshops were held to form the lists of KPIs. The workshops were participated by building maintenance personnel, building owners and research scientists. The both workshops had about ten attendees.

The literature search did not reveal which energy- and indoor-related information office occupants are interested in. A need to study that was apparent. Because views of single persons are supposed to be divergent, a quantitative research method was chosen to be implemented. The lists of potentially interesting information were discussed in workshops to form the questionnaire to be filled by office occupants.

The aim of the work presented in this paper is to study which energy- and indoor-related information office occupants are interested in. The preferences of office occupants are valuable to know for increasing occupant satisfaction in office environment and searching the most effective ways to reduce office energy consumption. (The KPI work dealing with other user groups than occupants is out of scope of this paper.)

\section{Method}

A questionnaire was given out to study the views of occupants in two office buildings. Building 1 and Building 2 are both located in Otaniemi district in Espoo, Finland. The buildings are occupied by VTT Technical Research Centre of Finland and Aalto University.

The simple purpose of the questionnaire was to find out which of the building-related information (measurements etc.) are most important to end-users in office buildings. The respondents were given 15 options from which they had to choose from one to five that were important to them (Table 1). They also had a possibility to give free comments.

Table 1. Options given to the respondents. The respondents were asked to choose from 1 to 5 options that they rated as the most important information for them in the office. A total of 97 respondents out of 151 chose 5 options, 27 chose 4 options, 18 chose 3 options, 5 chose 2 options and 4 chose 1 option. They also had an opportunity to add comments in their own words. In addition, background information (e.g. gender, age, education) was collected. Most of the respondents used the Finnish version of the questionnaire when answering, only 11 respondents out of 151 filled the English version. The English version is shown here.

\begin{tabular}{l} 
Room temperature in own office $\left({ }^{\circ} \mathrm{C}\right)$ \\
History of room temperature in own office $\left({ }^{\circ} \mathrm{C}\right)$ \\
Relative humidity of air in own office $(\%)$ \\
Lighting level in own office (lux) \\
Carbon dioxide $\left(\mathrm{CO}_{2}\right)$ concentration in own office (ppm) \\
Indoor air pollution concentration in own office (e.g., with a relative scale, \\
0 -1) \\
Operation status of air handling unit serving own office (on/off) \\
Instant values of energy consumption in own office (power) (W) \\
Energy consumption of own office (in a day / month / week) (kWh) \\
Comparison of energy consumption of own office with other similar offices \\
(difference, \%) \\
The cost of energy consumption of own office (in a day / month / week) (€) \\
Breakdown of energy consumption in own office (information on what \\
proportion is consumed by each appliance) $(\%)$ \\
General guidance for energy saving \\
Tailored guidance for energy saving - what is the most effective way to save \\
energy currently in this situation in this room \\
Local weather (temperature, rain, wind, sunniness/cloudiness) \\
\hline
\end{tabular}


The list of 15 options was defined based on discussions in workshops among experts in the field (see Section 1.3). The questionnaire was not specific to the buildings in the study; the idea was to gather information on the views of office occupants in general (as stated in the questionnaire).

Many of the occupants working in Building 1 are scientists in different fields of technology (many of them in the fields of buildings and communities) but other personnel also work in this building (including travel management, payroll and employment services, human resources development and group finance control). Most of the occupants in Building 1 had previously worked in a building with a serious indoor air problem. The reasons for the sick building syndrome symptoms of several years duration were not found during this time. To solve the problems the building went under renovation and the occupants moved to Building 1. The majority of the respondents in Building 2 are scientists in different fields of technology.

The paper questionnaire was delivered in April 2013 to Building 1. During this time the outdoor temperature was around $0^{\circ} \mathrm{C}$. The temperature was considerably higher (around $15^{\circ} \mathrm{C}$ ) in May when the questionnaire was delivered to Building 2 .

A total of 101 completed questionnaires were received from Building 1, and 225 were delivered, so the response rate was $45 \%$. These figures do not include the three respondents who did not fill in the questionnaire correctly, marking more than five options. Their responses were omitted from the analysis. A total of 50 completed questionnaires were received from Building 2. Of these, 165 were delivered, so the response rate was $30 \%$. Table 2 shows the number of respondents by gender, age and education.

Independent t-tests were performed to compare each dependent variable between genders, education groups and buildings. The significance level of difference was set at $5 \%$ $(\mathrm{p}<0.05)$.

Table 2. Number of respondents by gender, age and education.

\begin{tabular}{l|l|l}
\hline & Building 1 & Building 2 \\
\hline Total number of respondents & $101(100 \%)$ & $50(100 \%)$ \\
Females & $51(50 \%)$ & $18(36 \%)$ \\
Males & $47(47 \%)$ & $31(62 \%)$ \\
Gender not known & $3(3 \%)$ & $1(2 \%)$ \\
\hline $15-19$ & $1(1 \%)$ & $0(0 \%)$ \\
\hline $20-29$ & $12(12 \%)$ & $11(22 \%)$ \\
\hline $30-39$ & $28(28 \%)$ & $20(40 \%)$ \\
\hline $40-49$ & $23(23 \%)$ & $8(16 \%)$ \\
\hline $50-59$ & $30(30 \%)$ & $9(18 \%)$ \\
$60-99$ & $5(5 \%)$ & $2(4 \%)$ \\
\hline Age not known & $2(2 \%)$ & $0(0 \%)$ \\
\hline No degree / education in technology & $42(42 \%)$ & $13(26 \%)$ \\
\hline Degree / education in technology & $57(56 \%)$ & $35(70 \%)$ \\
\hline Education not known & $2(2 \%)$ & $2(4 \%)$ \\
\hline
\end{tabular}

\section{Results}

The principal findings were as follows. The most important information for the respondents in the study was (Table 3)

1. "room temperature in own office" $(77 \%)$

2. "indoor air pollution concentration in own office (e.g., with a relative scale, $0-1)$ " $(51 \%)$

3. "local weather (temperature, rain, wind, sunniness/cloudiness)" (41\%)

Information on indoor air was more important to the respondents than information on energy consumption/use. Of the respondents, $44 \%$ were not interested in energy-related information at all (Table 4). The corresponding percentage for indoor-related information is $3 \%$, i.e. $97 \%$ of the respondents were interested in information on indoor air. One of the respondents explained his view on energy consumption clearly: "Energy consumption is important for the employer/building owner/tenant (depending on who is responsible for the costs) but not for the end-users working in the office."

The most wanted information on energy consumption/use was the following:

1. "tailored guidance for energy saving - what is the most effective way to save energy currently in this situation in this room" (24\%)

2. "breakdown of energy consumption in own office, i.e. information on what proportion is consumed by each appliance (\%)" (22\%)

$7 \%$ of the respondents were interested in the cost of the energy consumption of their own office. $14 \%$ of the respondents were interested in "instant values of energy consumption in own office (power) (W)". The respondents were more interested in receiving tailored guidance on energy saving than general guidance (24\% vs $9 \%$ ). $15 \%$ of the respondents chose three or more energy-related options.

Principal differences between the sub-groups (Table 3) with statistical significances:

- Females were more interested than males in receiving both "general guidance for energy saving" $(p=0.029)$ and "tailored guidance for energy saving" ( $\mathrm{p}=$ $0.00005)$.

- Those who have no educational background in technology were more interested in receiving "general guidance for energy saving" than those with an educational background in technology $(p=0.017)$.

- Occupants in Building 1 were more interested in "indoor air pollution concentration in own office" than occupants in Building $2(\mathrm{p}=0.0009)$.

- Those who have an educational background in technology were more interested in "history of room temperature in own office" $(\mathrm{p}=0.0001)$ and "carbon dioxide $\left(\mathrm{CO}_{2}\right)$ concentration in own office" $(\mathrm{p}=0.004)$ and less interested in "indoor air pollution concentration in own office" $(p=0.017)$ and "lighting level in own office" ( $p=0.002$ ) than those who do not have an educational background in technology. 
Table 3. Results from the questionnaire: most important information arranged in order of popularity. Percentages show differences between the sub-groups. The total number of respondents was 151.

\begin{tabular}{|c|c|c|c|c|c|c|c|c|}
\hline & $\begin{array}{l}\text { Respondents who } \\
\text { consider this one of } \\
\text { the most important } \\
\text { pieces of information }\end{array}$ & All & Females & Males & $\begin{array}{l}\text { No education / } \\
\text { degree in } \\
\text { technology }\end{array}$ & $\begin{array}{l}\text { Education } \\
\text { / degree in } \\
\text { technology }\end{array}$ & Building 1 & Building 2 \\
\hline Room temperature in own office $\left({ }^{\circ} \mathrm{C}\right)$ & 117 & $77 \%$ & $81 \%$ & $74 \%$ & $87 \%$ & $72 \%$ & $83 \%$ & $66 \%$ \\
\hline $\begin{array}{l}\text { Indoor air pollution concentration in own office } \\
\text { (e.g., with a relative scale, } 0-1 \text { ) }\end{array}$ & 77 & $51 \%$ & $57 \%$ & $44 \%$ & $64 \%$ & $43 \%$ & $60 \%$ & $32 \%$ \\
\hline $\begin{array}{l}\text { Local weather (temperature, rain, wind, } \\
\text { sunniness/cloudiness) }\end{array}$ & 62 & $41 \%$ & $43 \%$ & $41 \%$ & $40 \%$ & $43 \%$ & $39 \%$ & $46 \%$ \\
\hline $\begin{array}{l}\text { Carbon dioxide }\left(\mathrm{CO}_{2}\right) \text { concentration in own } \\
\text { office (ppm) }\end{array}$ & 58 & $38 \%$ & $35 \%$ & $42 \%$ & $24 \%$ & $47 \%$ & $36 \%$ & $44 \%$ \\
\hline $\begin{array}{l}\text { Operation status of air handling unit serving own } \\
\text { office (on/off) }\end{array}$ & 51 & $34 \%$ & $33 \%$ & $32 \%$ & $33 \%$ & $33 \%$ & $34 \%$ & $34 \%$ \\
\hline Lighting level in own office (lux) & 49 & $32 \%$ & $41 \%$ & $24 \%$ & $47 \%$ & $22 \%$ & $35 \%$ & $28 \%$ \\
\hline Relative humidity of air in own office (\%) & 45 & $30 \%$ & $28 \%$ & $32 \%$ & $29 \%$ & $29 \%$ & $29 \%$ & $32 \%$ \\
\hline History of room temperature in own office $\left({ }^{\circ} \mathrm{C}\right)$ & 44 & $29 \%$ & $19 \%$ & $40 \%$ & $13 \%$ & $40 \%$ & $26 \%$ & $36 \%$ \\
\hline $\begin{array}{l}\text { Tailored guidance for energy saving - what is the } \\
\text { most effective way to save energy currently in } \\
\text { this situation in this room }\end{array}$ & 36 & $24 \%$ & $39 \%$ & $10 \%$ & $31 \%$ & $20 \%$ & $26 \%$ & $20 \%$ \\
\hline $\begin{array}{l}\text { Breakdown of energy consumption in own office } \\
\text { (information on what proportion is consumed by } \\
\text { each appliance) (\%) }\end{array}$ & 33 & $22 \%$ & $22 \%$ & $23 \%$ & $22 \%$ & $23 \%$ & $25 \%$ & $16 \%$ \\
\hline $\begin{array}{l}\text { Energy consumption of own office (in a day / } \\
\text { month / week) (kWh) }\end{array}$ & 29 & $19 \%$ & $14 \%$ & $24 \%$ & $16 \%$ & $22 \%$ & $16 \%$ & $26 \%$ \\
\hline $\begin{array}{l}\text { Comparison of energy consumption of own } \\
\text { office with other similar offices (difference, \%) }\end{array}$ & 21 & $14 \%$ & $13 \%$ & $14 \%$ & $11 \%$ & $15 \%$ & $13 \%$ & $16 \%$ \\
\hline $\begin{array}{l}\text { Instant values of energy consumption in own } \\
\text { office (power) (W) }\end{array}$ & 21 & $14 \%$ & $10 \%$ & $18 \%$ & $13 \%$ & $14 \%$ & $9 \%$ & $24 \%$ \\
\hline General guidance for energy saving & 14 & $9 \%$ & $14 \%$ & $4 \%$ & $18 \%$ & $4 \%$ & $10 \%$ & $8 \%$ \\
\hline $\begin{array}{l}\text { The cost of energy consumption of own office } \\
\text { (in a day / month / week) (€) }\end{array}$ & 11 & $7 \%$ & $7 \%$ & $6 \%$ & $5 \%$ & $7 \%$ & $4 \%$ & $14 \%$ \\
\hline
\end{tabular}

Table 4. Results grouped: interest in information on indoor air and energy consumption. The total number of respondents was 151.

\begin{tabular}{lll}
\hline & Number of respondents & Percentage of respondents \\
\hline $\begin{array}{l}\text { Interest in indoor air. Respondents who chose at least one of the pieces of information on } \\
\text { indoor air (see the first seven options in Table 1) }\end{array}$ & 146 & $97 \%$ \\
$\begin{array}{l}\text { Interest in energy consumption. Respondents who chose at least one of the pieces of } \\
\text { information on energy consumption (see the next seven options in Table 1) }\end{array}$ & 85 & $56 \%$ \\
\hline
\end{tabular}

\section{Discussion}

\subsection{Indoor-Related Information Is Preferred}

The results show that information on indoor air was more important to the respondents than information on energy consumption/use. The most important information was "room temperature in own office", chosen by $77 \%$ of the respondents. The proportion of respondents interested in knowing the room temperature was even higher for the following reasons. Fourteen respondents who marked "history of room temperature in own office" as one of their choices did not choose "room temperature in own office". One of the respondents commented that she was interested in room temperature but already knew it (had a thermometer), so she did not choose the option. It is likely that this respondent was not the only one acting this way. In total, about $90 \%$ of the respondents were interested in knowing the room temperature.

The second and third most important pieces of information for the respondents were "indoor air pollution concentration in own office (e.g., with a relative scale, $0-1)$ " (51\%) and "local weather (temperature, rain, wind, sunniness/cloudiness)" (41\%). However, a clear difference between the buildings was recognized. The interest in knowing the "indoor air pollution concentration" was higher among occupants in Building 1, plausible because most of them had previously worked in a building with an indoor air problem. If people could trust the indoor conditions to be safe and healthy, there would be less need for such information.

It is technically easy to let the occupants know the room temperature, but it is much more difficult to provide information on the indoor air pollution concentration. Gases and particles are emitted from various sources and no single device is available for measuring the indoor air pollution concentration (though, for example, radon concentration can be measured). Building automation systems will not be able to provide such information in the near future if accuracy is targeted. It is worth considering whether the occupants should be provided with some information on the indoor air 
pollution concentration, even with lower accuracy. However, it is important to note that information has no value if it cannot be trusted by the occupants.

\subsection{Preferences Regarding Energy Feedback}

Introduction of this paper shows an overview of studies that give insight for designing energy feedback. The present study contributes to this understanding by studying the preferences of office occupants.

The results show that $15 \%$ of the respondents were highly interested in energy-related information since they chose three or more energy-related options. The most wanted information on energy consumption/use was "tailored guidance for energy saving - what is the most effective way to save energy currently in this situation in this room" and "breakdown of energy consumption in own office, i.e. information on what proportion is consumed by each appliance (\%)". These responses can be considered rational since this kind of information is useful in making wise decisions on own energy use. With this information, the office occupants find out about the highest consumers of energy and suggestions on how to save energy.

Schwartz et al. [13] studied domestic environments and suggested that feedback should use money as a unit. Only $7 \%$ of the respondents in the present study were interested in the cost of the energy consumption of their own office. This was the least wanted piece of information. A reason for the disinterest is the fact that office occupants are not responsible for the costs of energy consumption, e.g. [18]. Gunay et al. [27] found that the occupants who were not responsible for their energy bills maintained their apartments $2^{\circ} \mathrm{C}$ higher in the heating season than those who were responsible for their energy bills.

The energy consumption of the respondents' own office in $\mathrm{kWh}$ or instant values in $\mathrm{W}$ was neither preferred, although energy monitors on the market typically present that information.

Numerical values in $\mathrm{kWh}$ or $\mathrm{W}$ may be abstract for an average user and may not give much advice for making decisions regarding own energy use. The values are often affected considerably by various factors that are not controllable by the user. The energy used by air conditioning or heating is largely affected by the weather. The effect of the respondents' own behaviour is not easily identified and may be small compared with other factors affecting consumption.

A fuel gauge in a car gives understandable and useful information for making decisions on when to next visit a service station. Analogous presentations are commonly used on energy dashboards, i.e. the meters presenting energy consumption are often designed to look like fuel gauges or speedometers. However, this kind of visual presentations or consumptions presented in $\mathrm{kWh}$ or $\mathrm{W}$ do not give similar value to office occupants to those of a fuel meter or speedometer in a car, because consumption values do not only reflect own behaviour but are affected by temporal and external factors.

\subsection{How to Change Energy Behaviour in Offices}

The results show that the respondents had a low interest in energy-related information. Almost half (44\%) of the respondents were not interested in energy-related information at all since they chose none of the energy-related options (Table 4).

An important question is whether we should provide energy-related information to everyone, even though a large proportion of office occupants are not interested in it. Does energy-related information have an effect on energy use among those who are not interested in it? Can uninteresting information motivate behaviour change? We should not be optimistic about this. However, Chiang et al. [28] reported energy savings in six-week experiments at student residences even though the participants were not engaged in the energy display. In this study, the energy savings may have been supported by the financial rewards given, the competitive element involved or the Hawthorne effect, as discussed by the authors.

Although the respondents did not prefer to receive comparative feedback ( $14 \%$ of them were interested in comparison of energy consumption of own office with other similar offices), it may be effective in reducing energy consumption. Normative social influence affected the energy use in the following studies performed in other contexts than offices. Nolan et al. [29] studied energy conservation in Californian households and found that normative social influence affects energy behaviour, i.e. "witnessing the actions of other people has a powerful effect on behaviour". Despite the fact that the participants believed that the behaviour of their neighbours had a very limited effect on their own behaviour, the results showed that this actually had the strongest effect on the participants' energy conservation behaviour. People seem to hold incorrect beliefs of what motivates them. The behaviour of others motivated them to conserve energy, although they did not realize that by themselves. Jain et al. [30] obtained similar results in an empirical experiment in a New York City residential building: social influence can drive energy conservation. Siero et al. [31] examined energy-related behaviour in a metallurgical company. They found that employees who received comparative feedback saved more energy than those who only received information about their own performance. There were hardly any changes in attitudes or intentions. This means that comparative feedback may have a potential to affect energy-related behaviour in office buildings despite the fact that people may say that they are not interested in comparing their consumption with that of others.

Social rewards and environmental considerations may motivate energy conservation in offices. Handgraaf et al. [24] found that public social rewards were more effective than monetary rewards in reducing energy use in the workplace. Spence et al. [32] note that the climate change concerns increase environmental behaviour intentions and energy saving. Jain et al. [10] found that feedback in equivalent 
number of trees was more effective in reducing consumption than feedback in energy units (kWh). Leygue [33] classified the types of motivation to save energy at work as self-directed (involving self-image and a 'warm glow') and altruistic (oriented toward the planet and toward the organisation). Her survey in UK workplaces showed that people are motivated mostly by environmental considerations.

It seems that office occupants cannot be motivated by the energy costs since they are not responsible for them. Normative social influence, public social rewards and climate change concerns may be more effective in contributing energy efficient behaviour.

\subsection{Limitations}

The questionnaire study was performed in two office buildings only. The respondents do not necessarily represent the views of the whole office population in Finland and elsewhere. Their views were studied by a questionnaire, i.e. the respondents did not actually receive the energy- and indoor-related information they were asked to choose between. Their preferences are prone to change when they receive and experience that information in real situations.

\section{Conclusions}

The results of this study show that the respondents in the study were more interested in receiving indoor-related information than energy-related information. The respondents were especially interested in knowing the room temperature in their own office. Almost half of the respondents were not interested in energy-related information at all since they chose none of the energy-related options. The most wanted information on energy consumption/use is "tailored guidance for energy saving - what is the most effective way to save energy currently in this situation in this room" and "breakdown of energy consumption in own office, i.e. information on what proportion is consumed by each appliance (\%)". The questionnaire study was performed in two office buildings in Finland. Future studies replicating the work elsewhere would be valuable in improving our understanding of the views of office occupants.

\section{Acknowledgements}

The work has been supported by K-MEG (Korea Micro Energy Grid) project and the Evidence project funded by the Academy of Finland.

\section{References}

[1] Lucon O, Ürge-Vorsatz D, Zain Ahmed A, et al. Buildings. In Edenhofer O, Pichs-Madruga R, Sokona Y, et al. (eds). Climate Change 2014: Mitigation of Climate Change. Contribution of Working Group III to the Fifth Assessment Report of the Intergovernmental Panel on Climate Change. Cambridge,
United Kingdom and New York, NY, USA: Cambridge University Press; 2014, pp. 671-738.

[2] Darby S. Making it Obvious: Designing Feedback into Energy Consumption. In Bertoldi P, Ricci A and de Almeida A (eds). Energy Efficiency in Household Appliances and Lighting, Energy Efficiency in Household Appliances and Lighting. Berlin: Springer-Verlag; 2001, pp 685-696.

[3] Abrahamse W, Steg L, Vlek C, et al. A review of intervention studies aimed at household energy conservation. J Environ Psychol 2005; 25: 273-291.

[4] Fischer C. Feedback on household electricity consumption: a tool for saving energy? Energy Efficiency 2008; 1: 79-104.

[5] Ehrhardt-Martinez K, Donnelly KA and Laitner JA. Advanced Metering Initiatives and Residential Feedback Programs: A Meta-review for Household Electricity Saving Opportunities. Washington, DC: Washington, DC, 2010.

[6] Faruqui A, Sergici S and Sharif A. The impact of informational feedback on energy consumption-A survey of the experimental evidence. Energy 2010; 35: 1598-1608.

[7] Karjalainen S. Consumer preferences for feedback on household electricity consumption. Energy Build 2011; 43: 458-467.

[8] Krishnamurti T, Davis AL, Wong-Parodi G, et al. Creating an in-home display: Experimental evidence and guidelines for design. Appl Energy 2013; 108: 448-458.

[9] Jain RK, Taylor JE and Peschiera G. Assessing eco-feedback interface usage and design to drive energy efficiency in buildings. Energy Build 2012; 48: 8-17.

[10] Jain RK, Taylor JE and Culligan PJ. Investigating the impact eco-feedback information representation has on building occupant energy consumption behavior and savings. Energy Build 2013; 64: 408-414.

[11] Hargreaves T, Nye M and Burgess J. Making energy visible: A qualitative field study of how householders interact with feedback from smart energy monitors. Energ Policy 2010; 38: 6111-6119.

[12] Chiang T, Natarajan S and Walker I. A laboratory test of the efficacy of energy display interface design. Energy Build 2012; 55: 471-480.

[13] Schwartz T, Stevens G, Ramirez L, et al. Uncovering Practices of Making Energy Consumption Accountable: A Phenomenological Inquiry. ACM Trans. Comput.-Hum. Interact. 2013; 20: 12:1-12:30.

[14] Pierce J and Paulos E. Beyond Energy Monitors: Interaction, Energy, and Emerging Energy Systems. In Proceedings of the SIGCHI Conference on Human Factors in Computing Systems, Austin, Texas, USA, May 5-12, 2012; New York, USA: ACM. 2012; pp. 665-674.

[15] Murtagh N, Nati M, Headley WR, et al. Individual energy use and feedback in an office setting: A field trial. Energ Policy 2013; 62: 717-728.

[16] Final energy consumption by sector (CSI 027/ENER 016). Copenhagen, Denmark: European Environment Agency (EEA), 2015.

http://www.eea.europa.eu/data-and-maps/indicators/final-energy -consumption-by-sector-8/assessment-2 (accessed 9 Jan 2015). 
[17] Coleman MJ, Irvine KN, Lemon M and Shao L. Promoting behaviour change through personalized energy feedback in offices. Build Res Inf 2013; 41: 637-651.

[18] Karjalainen S. The Characteristics of Usable Room Temperature Control. Espoo: VTT Technical Research Centre of Finland; 2007.

[19] Oseland NA. Predicted and reported thermal sensation in climate chambers, offices and homes. Energy Build 1995; 23: 105-115.

[20] Karjalainen S. Thermal comfort and use of thermostats in Finnish homes and offices. Build Environ 2009; 44: $1237-1245$.

[21] Littleford C, Ryley TJ and Firth SK. Context, control and the spillover of energy use behaviours between office and home settings. J Environ Psychol 2014; 40: 157-166.

[22] Carrico AR and Riemer M. Motivating energy conservation in the workplace: An evaluation of the use of group-level feedback and peer education. J Environ Psychol 2011; 31: 1-13.

[23] Orland B, Ram N, Lang D, Houser K, Kling N and Coccia M. Saving energy in an office environment: A serious game intervention, Energy Build 2014; 74: 43-52.

[24] Handgraaf MJJ, Van Lidth de Jeude, rgriet A. and Appelt KC. Public praise vs. private pay: Effects of rewards on energy conservation in the workplace. Ecol Econ 2013; 86: 86-92.

[25] Yun R, Lasternas B, Aziz A, et al. Toward the Design of a Dashboard to Promote Environmentally Sustainable Behavior among Office Workers. Persuasive Technology: Lect Notes Comp Sc 2013; 7822: 246-252.
[26] Börner D, Storm J, Kalz M, et al. Energy Awareness Displays: Motivating Conservation at the Workplace Through Feedback. Int J Mob Learn Organ 2012; 6: 189-203.

[27] Gunay HB, O'Brien W, Beausoleil-Morrison A and Perna, A. On the behavioral effects of residential electricity submetering in a heating season. Build Environ 2014; 81: 396-403.

[28] Chiang T, Mevlevioglu G, Natarajan S, et al. Inducing [sub] conscious energy behaviour through visually displayed energy information: A case study in university accommodation. Energy Build 2014; 70: 507-515.

[29] Nolan JM, Schultz PW, Cialdini RB, et al. Normative Social Influence is Underdetected. Per Soc Psychol B 2008; 34: 913-923

[30] Jain RK, Gulbinas R, Taylor JE, et al. Can social influence drive energy savings? Detecting the impact of social influence on the energy consumption behavior of networked users exposed to normative eco-feedback. Energy Build 2013; 66: 119-127.

[31] Siero FW, Bakker AB, Dekker GB, et al. Changing organizational energy consumption behaviour through comparative feedback. J Environ Psychol 1996; 16: 235-246.

[32] Leygue C. Saving energy in the workplace; why, and for whom? In Proceeding of Behave Conference, Sept 3-4, 2014; Oxford, UK: Saïd Business School; 2014.

[33] Spence A, Leygue C, Bedwell B and O'Malley C. Engaging with energy reduction: Does a climate change frame have the potential for achieving broader sustainable behaviour? J Environ Psychol 2014; 38: 17-28. 